\title{
Interracial Bridging Social Capital among Students of a Multicultural University in
}

\section{Malaysia}

\begin{abstract}
In this study, the influence of interracial socialization and race on interracial bridging social capital among Malaysian students of a multicultural Malaysian public university was examined. Results reveal a narrowed level of interracial bridging social capital among the students. The minority Chinese and the majority Malays do not differ in their level of interracial social capital, but the minority Indians has a significantly higher level of interracial bridging social capital in comparison. The level of interracial socialization with peers directly and significantly affects the level of interracial bridging social capital for all three racial groups. No interaction effect of race and interracial socialization frequency on interracial bridging social capital is found. The implications of the findings are discussed.
\end{abstract}

Keyword: Interracial Bridging; Social Capital; Multicultural University; Malaysia 